02

\title{
Спектрально-люминесцентные свойства соединений европия (III) с двумя различными $\beta$-дикетонами
}

\author{
(C) И.В. Калиновская \\ Институт химии Дальневосточного отделения РАН, \\ 690022 Владивосток, Россия \\ e-mail: kalinovskaya@ich.dvo.ru
}

Поступила в редакцию 12.07.2017 г.

Получены люминесцирующие комплексные разнолигандные соединения европия(III) с двумя различными $\beta$-дикетонами. Изучены спектрально-люминесцентные свойства комплексных соединений европия(III). Совместное присутствие в координационной сфере европия(III) двух различных $\beta$-дикетонов приводит к расширению спектрального диапазона поглощения и росту интенсивности люминесценции.

DOI: $10.21883 /$ OS.2018.03.45648.217-17

В связи с разработкой функциональных оптических полимерных материалов для нужд оптоэлектроники, лазерной техники, сенсорики актуальным является поиск новых люминесцирующих комплексных соединений лантаноидов [1-6].

Перспективным классом комплексных соединений редкоземельных элементов (РЗЭ) являются интенсивно люминесцирующие $\beta$-дикетонаты лантаноидов. Сведения о синтезе и изучении физико-химических свойств соединений лантанидов с двумя различными $\beta$-дикетонами в координационной сфере ограничены [7-9]. Синтезировать данные комплексные соединения сложно, из реакционной смеси кристаллизуется осадок, содержащий несколько соединений. С целью изучения условий существования, состава и строения комплексных соединений европия с двумя различными $\beta$-дикетонами проведено исследование ЯМР $\left({ }^{1} \mathrm{H},{ }^{19} \mathrm{~F}\right)$ систем $\mathrm{Eu}(\beta \text {-dic })_{3} \cdot$ phen- $\mathrm{CdCl}_{3}-(\beta \text {-dic })^{*}[10,11]$. Полученный в данных работах ряд взаимного замещения $\beta$-дикетонов позволяет решить вопрос о путях синтеза разнолигандных соединений РЗЭ и предсказать направление реакций внутрисферного замещения в системах, содержащих несколько различных $\beta$-дикетонов, а данные о количественном соотношении между конкурирующими лигандами помогают установить оптимальные условия получения соединений заданного состава необходимой чистоты. В работах $[10,11]$ установлено, что $\beta$-дикетоны с высокими акцепторными свойствами заместителей $\beta$-дикетонов обладают большей конкурентной способностью. Процесс вытеснения $\beta$-дикетонов из координационной сферы европия в исследуемых трис-комплексах происходит через ступенчатое замещение последних с образованием комплексов $\left[\mathrm{Eu}(\beta \text {-dic })_{3-n}(\beta \text {-dic })_{n}^{*}\right]$ phen, где $n=1-3$.

В настоящем сообщении представлены результаты изучения спектрально-люминесцентных свойств комплексных соединений европия(III) с двумя различными $\beta$-дикетонами состава $\mathrm{Eu}(\beta$-dic $)(\beta \text {-dic })_{2}^{*} \cdot 2 \mathrm{H}_{2} \mathrm{O}, \quad$ где $\beta$-dic $\neq \beta$-dic*. В качестве лигандов выбраны $\beta$-дикетоны, обладающие различными электронодонорными свой- ствами: ацетилацетон (Насас), бензоилацетон (Hbzac), дибензоилметан (Hdbm), трифторацетилацетон (Htfac), теноилтрифторацетон (Htta), бензоилтрифторацетон (Hbtfac), гексафторацетилацетон (Hhfac).

\section{Экспериментальная часть}

Для синтеза комплексных соединений состава $\mathrm{Eu}(\beta$-dic $)(\beta \text {-dic })_{2}^{*} \cdot 2 \mathrm{H}_{2} \mathrm{O}$ использовали следующие препараты марки „ч““: шестиводный хлорид европия(III), $\beta$-дикетоны. Ацетилацетон дополнительно очищали перегонкой. Комплексные соединения европия(III) с двумя различными $\beta$-дикетонами состава $\mathrm{Eu}(\beta \text {-dic })_{3-n}(\beta \text {-dic })_{n}^{*} \cdot 2 \mathrm{H}_{2} \mathrm{O}$, где $n=1,2, \beta$-dic - hfac, $\mathrm{tfac}, \mathrm{tta}, \mathrm{dbm}$, bzac, асас синтезированы при смешивании бензольного раствора $\beta$-дикетонов и водного раствора хлорида европия в мольном отношении Eu: $\beta$-dic: $\beta$-dic ${ }^{*}=1:(1-2):(1-2) .10 \%$-ным раствором $\mathrm{NH}_{4} \mathrm{OH}$ поддерживали $\mathrm{pH}$ раствора, равным 6.5-7.0. Выпавшие осадки отфильтровали, промывали воднобензольной смесью, сушили на воздухе. Выход составил $85-87 \%$.

Полученные комплексные соединения представляют собой мелкокристаллические порошки, нерастворимые в воде, растворимые в большинстве неполярных и полярных растворителей.

Низкотемпературные спектры люминесценции регистрировали на спектрометре СДЛ-1. Возбуждение осуществляли ртутной лампой ДРШ-250. Ошибка измерений не превышала $\pm 2-3 \mathrm{~cm}^{-1}$. Шкала длин волн спектрометра СДЛ-1 выверялась по линиям гелий-неонового источника и дублета ртути 576 и $579 \mathrm{~nm}$. Электронные спектры поглощения регистрировали на спектрометре RF-2550 Shimadzu, а спектры возбуждения люминесценции - на приборе RF-5301 Shimadzu. Элементным анализом установлено содержание С и Н в синтезированных комплексных соединениях европия(III), содержание воды - титрованием по Фишеру (табл. 1). 
Таблица 1. Данные химического элементного анализа для комплексных соединений европия(III) с двумя различными $\beta$-дикетонами

\begin{tabular}{|c|c|c|c|c|c|c|c|c|c|}
\hline \multirow{2}{*}{ Соединение } & \multicolumn{4}{|c|}{ Найдено, \% } & \multicolumn{4}{|c|}{ Вычислено, \% } & \multirow{2}{*}{$T_{\text {разлл }},{ }^{\circ} \mathrm{C}$} \\
\hline & $\mathrm{C}$ & $\mathrm{H}$ & $\mathrm{Eu}$ & $\mathrm{H}_{2} \mathrm{O}$ & $\mathrm{C}$ & $\mathrm{H}$ & $\mathrm{Eu}$ & $\mathrm{H}_{2} \mathrm{O}$ & \\
\hline $\mathrm{Eu}(\mathrm{acac})(\mathrm{hfac})_{2} \cdot 2 \mathrm{H}_{2} \mathrm{O}$ & 25.5 & 2.1 & 22.1 & 5.5 & 25.7 & 1.9 & 21.7 & 5.1 & $190-192$ \\
\hline $\mathrm{Eu}(\mathrm{acac})(\mathrm{tfac})_{2} \cdot 2 \mathrm{H}_{2} \mathrm{O}$ & 30.4 & 3.1 & 25.7 & 6.1 & 30.4 & 3.2 & 25.6 & 6.1 & $130-132$ \\
\hline $\mathrm{Eu}(\mathrm{acac})(\mathrm{tta})_{2} \cdot 2 \mathrm{H}_{2} \mathrm{O}$ & 34.3 & 3.0 & 20.0 & 5.3 & 34.6 & 2.6 & 20.4 & 4.9 & $148-152$ \\
\hline $\mathrm{Eu}(\mathrm{hfac})_{2}(\mathrm{tta}) \cdot 2 \mathrm{H}_{2} \mathrm{O}$ & 30.4 & 1.8 & 18.6 & 4.4 & 30.1 & 1.6 & 18.2 & 4.4 & $168-170$ \\
\hline $\mathrm{Eu}(\mathrm{tfac})(\mathrm{hfac})_{2} \cdot 2 \mathrm{H}_{2} \mathrm{O}$ & 23.6 & 1.6 & 20.3 & 5.2 & 23.8 & 1.3 & 20.1 & 4.8 & $162-164$ \\
\hline $\mathrm{Eu}(\mathrm{acac})(\mathrm{bzac})_{2} \cdot 2 \mathrm{H}_{2} \mathrm{O}$ & 48.9 & 4.7 & 23.5 & 5.9 & 49.3 & 4.8 & 25.0 & 5.9 & $153-155$ \\
\hline $\mathrm{Eu}(\mathrm{bzac})(\mathrm{tfac})_{2} \cdot 2 \mathrm{H}_{2} \mathrm{O}$ & 36.9 & 3.6 & 23.5 & 5.8 & 36.6 & 3.2 & 23.2 & 5.5 & $160-163$ \\
\hline $\mathrm{Eu}(\mathrm{bzac})(\mathrm{hfac})_{2} \cdot 2 \mathrm{H}_{2} \mathrm{O}$ & 31.8 & 2.2 & 20.2 & 4.8 & 31.5 & 2.0 & 19.9 & 4.7 & $173-175$ \\
\hline $\mathrm{Eu}(\mathrm{bzac})(\mathrm{tta})_{2} \cdot 2 \mathrm{H}_{2} \mathrm{O}$ & 39.6 & 3.0 & 19.5 & 5.7 & 39.4 & 2.7 & 19.2 & 5.5 & $166-169$ \\
\hline $\mathrm{Eu}(\mathrm{acac})(\mathrm{dbm})_{2} \cdot 2 \mathrm{H}_{2} \mathrm{O}$ & 57.6 & 5.1 & 20.3 & 5.2 & 57.3 & 4.5 & 20.7 & 4.9 & $120-124$ \\
\hline
\end{tabular}

По данным элементного химического анализа состав синтезированных комплексных соединений европия(III) отвечает формуле $\mathrm{Eu}(\beta$-dic $)(\beta \text {-dic })_{2}^{*} \cdot 2 \mathrm{H}_{2} \mathrm{O}$.

\section{Результаты и их обсудение}

Используя данные ЯМР $\left({ }^{1} \mathrm{H},{ }^{19} \mathrm{~F}\right)$ по взаимному замещению $\beta$-дикетонов, создавая определенные значения $\mathrm{pH}$ раствора, были синтезированы комплексные соединения с двумя различными $\beta$-дикетонами состава $\mathrm{Eu}(\beta$-dic $)(\beta \text {-dic })_{2}^{*} \cdot 2 \mathrm{H}_{2} \mathrm{O}[9-11]$.

Полученные разнолигандные комплексные соединения европия(III) устойчивы на воздухе, не разлагаются при длительном хранении.

ИК спектры каждого синтезированного нами комплексного соединения представляют набор частот, характерных для двух различных $\beta$-дикетонов [12]. Однако интерпретация ИК спектров полученных комплексов затруднена из-за наложения полос колебаний отдельных групп $\beta$-дикетонов, координируемых ионом европия(III). Данные ИК спектроскопического исследования „свободных“ $\beta$-дикетонов в енольной форме приведены в [12]. Отсутствие в ИК спектрах исследуемых комплексных соединений полос поглощения, характерных для группы $\mathrm{C}=\mathrm{O}$ „свободных“ $\beta$-дикетонов, и появление двух интенсивных полос поглощения в области более низких частот $1957-1651 \mathrm{~cm}^{-1}$ свидетельствуют о бидентатной координации двух различных $\beta$-дикетонов кислородными атомами карбонильных групп к центральному атому европия. Бидентатный способ координации $\beta$-дикетонов к иону европия подтверждают и данные ЯМР $\left({ }^{1} \mathrm{H},{ }^{19} \mathrm{~F}\right)$. Из анализа температурной зависимости спектров ЯМР $\left({ }^{1} \mathrm{H},{ }^{19} \mathrm{~F}\right)$ изучаемых систем следует, что исходные и образующиеся в процессе замещения комплексные соединения европия(III) имеют одинаковый способ координации лигандов. В полученных гидратах трис- $\beta$-дикетонатах три бидентатных $\beta$-дикетона атомами кислорода координируются к иону европия(III) [10,11].
УФ спектроскопическое исследование также подтверждает образование комплексных соединений европия(III) с двумя различными $\beta$-дикетонами в координационной сфере. Электронные спектры поглощения исследуемых комплексных соединений представлены на
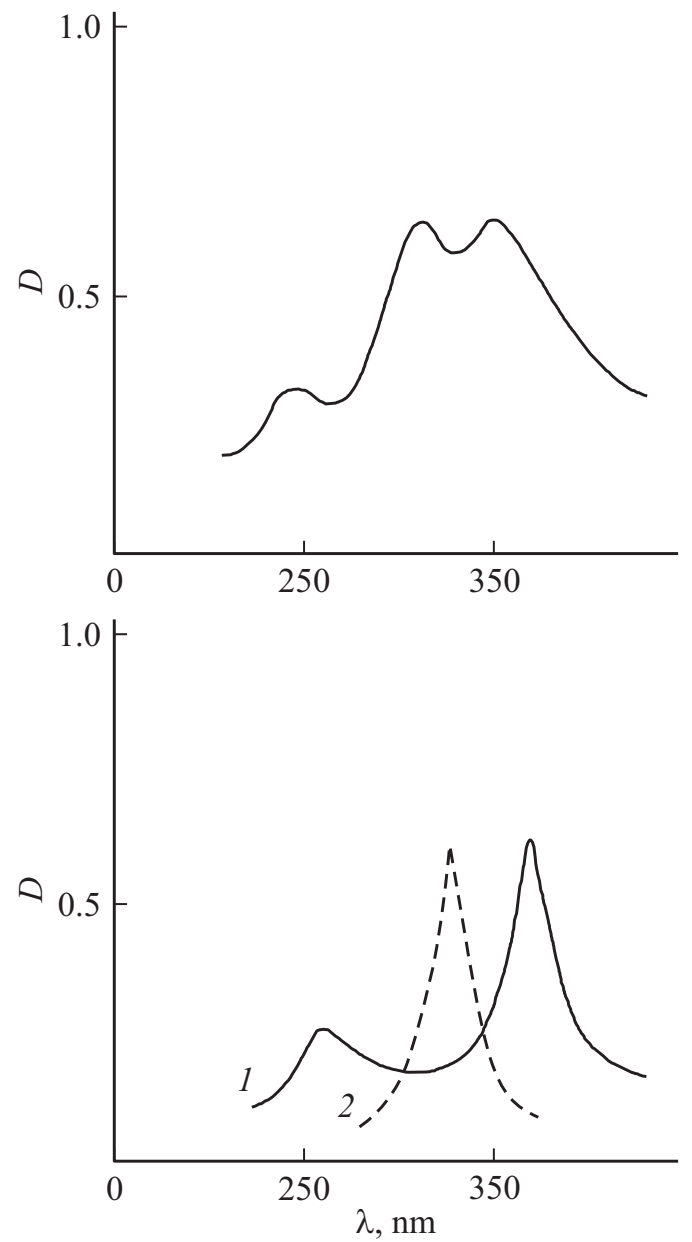

$b$

Рис. 1. Электронные спектры поглощения растворов в этаноле $\left(10^{-4} \mathrm{M}\right):$ (a) $\mathrm{Eu}(\mathrm{acac})(\mathrm{bzac})_{2} \cdot 2 \mathrm{H}_{2} \mathrm{O},($ b) Hbzac (1), Hacac (2). 
Таблица 2. Интенсивность люминесценции разнолигандных соединений европия с $\beta$-дикетонами, где $I$ - интегральная интенсивность электродипольного перехода ${ }^{5} D_{0}-{ }^{7} F_{2}$, $\lambda_{\text {возб }}=365 \mathrm{~nm}$

\begin{tabular}{l|l}
\hline \multicolumn{1}{c|}{ Соединение } & $I$ \\
\hline $\mathrm{Eu}(\mathrm{tta})(\mathrm{hfac})_{2} \cdot 2 \mathrm{H}_{2} \mathrm{O}$ & 0.5 \\
$\mathrm{Eu}(\mathrm{tfac})(\mathrm{hfac})_{2} \cdot 2 \mathrm{H}_{2} \mathrm{O}$ & 1.0 \\
$\mathrm{Eu}(\mathrm{hfac})_{3} \cdot 2 \mathrm{H}_{2} \mathrm{O}$ & 0.4 \\
$\mathrm{Eu}(\mathrm{tfac})_{3} \cdot 2 \mathrm{H}_{2} \mathrm{O}$ & 0.3 \\
$\mathrm{Eu}(\mathrm{btfac})(\mathrm{hfac})_{2} \cdot 2 \mathrm{H}_{2} \mathrm{O}$ & 0.8 \\
$\mathrm{Eu}(\mathrm{acac})(\mathrm{hfac})_{2} \cdot 2 \mathrm{H}_{2} \mathrm{O}$ & 0.6 \\
$\mathrm{Eu}(\mathrm{acac})(\mathrm{tta})_{2} \cdot 2 \mathrm{H}_{2} \mathrm{O}$ & 0.6 \\
$\mathrm{Eu}(\mathrm{acac})(\mathrm{tfac})_{2} \cdot 2 \mathrm{H}_{2} \mathrm{O}$ & 0.5 \\
$\mathrm{Eu}(\mathrm{bzac})(\mathrm{hfac})_{2} \cdot 2 \mathrm{H}_{2} \mathrm{O}$ & 0.5 \\
$\mathrm{Eu}(\mathrm{bzac})(\mathrm{tfac})_{2} \cdot 2 \mathrm{H}_{2} \mathrm{O}$ & 0.45 \\
$\mathrm{Eu}(\mathrm{bzac})(\mathrm{dbm})_{2} \cdot 2 \mathrm{H}_{2} \mathrm{O}$ & 0.45 \\
$\mathrm{Eu}(\mathrm{acac})(\mathrm{bzac})_{2} \cdot 2 \mathrm{H}_{2} \mathrm{O}$ & 0.45 \\
$\mathrm{Eu}(\mathrm{acac})(\mathrm{dbm})_{2} \cdot 2 \mathrm{H}_{2} \mathrm{O}$ & 0.4 \\
$\mathrm{Eu}(\mathrm{acac})_{3} \cdot 3 \mathrm{H}_{2} \mathrm{O}$ & 0.25 \\
$\mathrm{Eu}(\mathrm{dbm})_{3} \cdot 2 \mathrm{H}_{2} \mathrm{O}$ & 0.28
\end{tabular}

рис. 1. Для сравнения представлены и электронные спектры поглощения соответствующих $\beta$-дикетонов, входящих в состав координационной сферы европия(III). Проведенный анализ электронных спектров поглощения показывает, что комплексообразование практически не оказывает влияния на положение и форму полос, соответствующих $\pi-\pi^{*}$-переходам координируемых $\beta$-дикетонов. Для синтезированных соединений европия(III) с двумя различными $\beta$-дикетонами характерен более сложный вид спектров поглощения, чем для „обычных“ трис- $\beta$-дикетонатов европия, а именно наличие трех-четырех полос примерно равной интенсивности в области $200-360 \mathrm{~nm}$, соответствующих $\pi-\pi^{*}$-переходам двух различных $\beta$-дикетонов. В видимой области спектра $(450-520 \mathrm{~nm})$ присутствуют малоинтенсивные полосы поглощения, соответствующие $f-f$-переходам РЗЭ.

В спектрах возбуждения люминесценции (рис. 2) присутствуют полосы $\pi-\pi$-переходов двух различных $\beta$-дикетонов, что приводит к эффективной передаче энергии с их триплетных уровней на ион европия и росту интенсивности люминесценции (табл. 2).

Интенсивность люминесценции полученных соединений с двумя различными $\beta$-дикетонами выше обычных трис-комплексов с однотипными $\beta$-дикетонами на $15-25 \%$. В табл. 2 приведены данные интегральной интенсивности линий электродипольного перехода ${ }^{5} D_{0}-{ }^{7} F_{2}\left(\lambda_{\text {возб }}=365 \mathrm{~nm}\right)$.

Полученные комплексные соединения европия уже при комнатной температуре обладают интенсивной люминесценцией красного цвета с максимумом при $612 \mathrm{~nm}$ (рис. 3). Спектры люминесценции, обусловленные электронными переходами внутри $4 f$-оболочки $\mathrm{Eu}^{3+}$, имеют дискретную структуру (рис. $3, a$ ).
Спектры люминесценции соединений европия с двумя различными $\beta$-дикетонами значительно отличаются от спектров люминесценции „обычных“ трис- $\beta$-дикетонатов европия, что указывает на образование индивидуальных соединений. Отличительная особенность спектров люминесценции полученных комплексов европия - довольно высокая интенсивность линии запрещенного электродипольного перехода ${ }^{5} D_{0}-{ }^{7} F_{0}$ (в спектрах люминесценции большинства трис- $\beta$-дикетонатов европия интенсивность данного перехода ниже). Причем

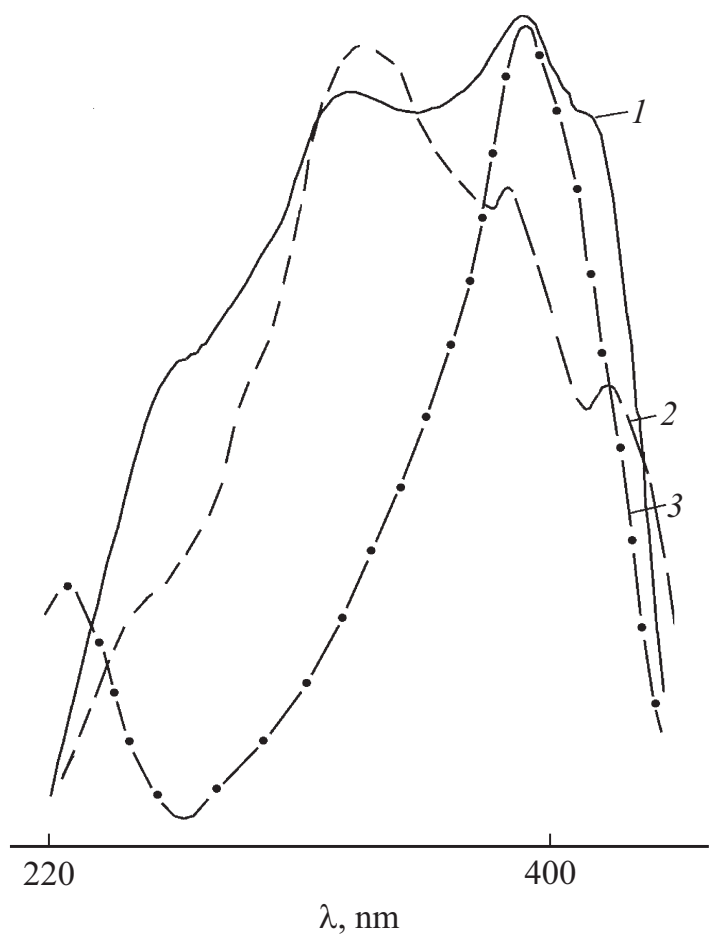

Рис. 2. Спектры возбуждения люминесценции соединений европия(III): $1-\mathrm{Eu}(\mathrm{bzac})(\mathrm{dbm})_{2} \cdot 2 \mathrm{H}_{2} \mathrm{O}, 2-\mathrm{Eu}(\mathrm{dbm})_{3} \cdot \mathrm{H}_{2} \mathrm{O}$, $3-\mathrm{Eu}(\mathrm{bzac})_{3} \cdot 2 \mathrm{H}_{2} \mathrm{O}$.

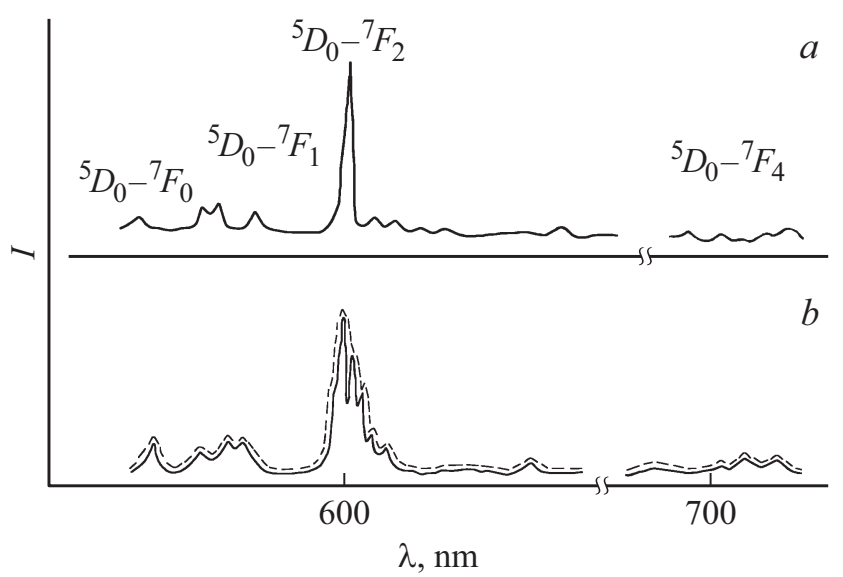

Рис. 3. Спектры люминесценции (77 К) соединений европия(III): (a) $\mathrm{Eu}(\mathrm{acac})(\mathrm{tfac})_{2} \cdot 2 \mathrm{H}_{2} \mathrm{O},(b) \mathrm{Eu}(\mathrm{acac})(\mathrm{hfac})_{2} \cdot 2 \mathrm{H}_{2} \mathrm{O}$, штриховая кривая - $\mathrm{Eu}(\mathrm{acac})(\mathrm{hfac})_{2} \cdot 2 \mathrm{H}_{2} \mathrm{O}$ в полиметилметакрилате. 
чем больше отличаются электронодонорные свойства $\beta$-дикетонов, входящих в состав координационной сферы европия, тем больше интенсивность электродипольного перехода ${ }^{5} D_{0}-{ }^{7} F_{0}$. Наличие в спектрах люминесценции полученных соединений максимально возможного числа компонент штарковской структуры переходов ${ }^{5} D_{0}-{ }^{7} F_{j}$ $(j=1-2)$, равного $2 j+1$, большая интенсивность перехода ${ }^{5} D_{0}-{ }^{7} F_{0}$ указывают на то, что симметрия центров люминесценции низкая, не выше $C_{2 v}$.

Распределение энергии излучения по переходам и отдельным линиям внутри перехода приблизительно одинаково во всех спектрах синтезированных комплексных соединений европия(III) с двумя различными $\beta$-дикетонами. Основная доля энергии излучения приходится на линии электродипольного перехода ${ }^{5} D_{0}-{ }^{7} F_{2}$. Причем интенсивность полос, соответствующих триплетному магнитно-дипольному переходу ${ }^{5} D_{0}-{ }^{7} F_{1}$, на порядок ниже интенсивности линий электродипольного перехода ${ }^{5} D_{0}-{ }^{7} F_{2}$. Регистрируемые в низкотемпературных спектрах величины расщеплений штарковских уровней ${ }^{7} F_{1,2}$ являются чувствительными индикаторами взаимодействия $\mathrm{Eu}^{3+}$ с координируемыми $\beta$-дикетонами. Наибольшее расщепление штарковских компонент термов ${ }^{7} F_{1}$ характерно для соединений с акцепторными заместителями состава $\mathrm{Eu}(\mathrm{acac})\left(\beta_{\mathrm{F}} \text {-dic }\right)_{2} \cdot 2 \mathrm{H}_{2} \mathrm{O}$, где $\beta_{\mathrm{F}}$-dic tfac, tta, hfac.

Для изготовления светопрозрачных материалов соединения, растворимые в органических растворителях и обладающие интенсивной и устойчивой во времени люминесценцией, испытаны в качестве активных добавок в полиметилметакрилатную матрицу (рис. $3, b$ ).

Таким образом, отличительной особенностью соединений европия(III) с двумя различными $\beta$-дикетонами является более сложный по сравнению с „обычными“ трис- $\beta$-дикетонатами европия(III) вид электронных спектров поглощения и возбуждения люминесценции. Это приводит к эффективной передаче энергии с триплетных уровней $\beta$-дикетонов на европий(III) и росту интенсивности люминесценции иона европия(III).

\section{Список литературы}

[1] Zhang J., Wang R., Bai J., Wang S. // J. Rare Earths. 2002. V. 20. N 5. P. 449.

[2] Zhang J., Wang R., Yang H. // Chin. J. Anal. Chem. 2003. V. 31. N 4. P. 472.

[3] Hasegawa Y., Nakanishi T. // RSC. Adv. 2015. V. 5. P. 338.

[4] Bunzli J.-C.G., Eliseeva S.V. // Chem. Sci. 2013. V. 4. N 5. P. 1913.

[5] Binnemans K. Rare-earth beta-diketonates. Handbook on the Physics and Chemistry of Rare Earths. Elsevier, 2005. V. 35. P. $107-272$.

[6] Kataoka H., Kitano T., Takizawa T., Hirai Y., Nakanishi T., Hasegawa Y. // J. Alloys Compd. 2014. V. 601. P. 293.

[7] Dutt N.K., Sur S. // J. Inorg. Nucl. Chem. 1971. V. 33. N 1. P. 115.

[8] Woo C., Wagner W.F., Sands D.E. // J. Inorg. Nucl. Chem. 1972. V. 34. N 1. P. 307.
[9] Калиновская И.В., Карасев В.Е. // Журн. неорган. химии. 1991. T. 36. № 12. С. 3102.

[10] Кавун В.Я., Карасев В.Е., Шукина И.В., Чернышов Б.Н. // Журн. неорган. химии. 1987. Т. 32. № 3. С. 591-595.

[11] Кавун В.Я., Калиновская И.В., Карасев В.Е. // Журн. неорган. химии. 1989. Т. 34. № 7. С. 1681.

[12] Накамото К. Инфракрасные спектры неорганических и координационных соединений. М.: Мир, 1966. 412 с. 